\title{
A MORAL REFORMADORA E A PRISÃO DE MENTALIDADES adolescentes sob o discurso penalizador
}

\author{
Salete Magda de Oliveira \\ Membro do Núcleo de Sociabilidade Libertária do Programa de Estudos Pós-Graduados da PUC-SP, Pesquisadora da Capes
}

1

sociedade ocidental insiste em reatualizar, sob inúmeras vestes, o legado da concepção de justiça da filosofia platônica. Parte do pressuposto de que justiça equivale ao bem, sob a ótica da moral; ao bem comum, como generalização legal; e à garantia da ordem pública, enquanto meta legitimadora de expurgos do que é considerado insuportável.

Criam-se, assim, dicotomias que alimentam o jogo de antagonismos coadunados à falaciosa pretensão que caminha lado a lado do ideal de felicidade. A denominação de mal-estar emerge complementada pelo seu oposto: o bem-estar, duplo equivalente e capaz de redenção. Tratase, mais uma vez, de fazer caber o outro no um, batalha de pólos contrários que rivalizam no mesmo espectro de intervenção e centralidade.

A tessitura do clamor de segurança disseminado pela sociedade exige que o bem-estar seja o modelo exemplar capaz de responder a mal-estares inerentes, construídos e cultivados sob a lógica do temor.

As conotações de bem-estar e mal-estar respondem à retórica que prima pela tautologia ${ }^{1}$ de uma sociabilidade que constrói e reconstrói intervenções reformistas, legitimadas pela edificação de seu próprio embaraço diante da escolha de uma moralidade do juízo providencial.

Não causa espanto que o espectro do tribunal incida, sob as mais variadas nuances, em diversas esferas da vida, muitas vezes de forma velada e doce, e, regularmente, como ritual soberano e disciplinar.

Cabe, assim, interrogar o significado da reinvenção e reiteração do tribunal em nossa sociedade, como locus depositário do justo e procedimento exemplar que responde aos anseios democráticos que clamam pelo fim da violência e da impunidade. Se a violência manifesta-se como uma das formas preferenciais de identificação do mal-estar, a resposta convencional esperada, que coabita vidas inseguras de si próprias, justifica não só a existência da prisão para jovens no Brasil e suas eternas reformas, bem como a manutenção dos dispositivos carcerários que encontram sua porta de entrada sob a forma de julgamento materializado no tribunal para adolescentes considerados infratores.

As consciências engajadas ao ideal da democracia encontram alívio na atuação de advogados, cumprindo um mero expediente formal que desqualifica seu papel de defesa; de juízes e promotores, garantindo a ordem e deixando intocada a propriedade privada como extensão da própria vida; e de técnicos que, sob pareceres biopsicosociais, legitimam a intervenção das chamadas ciências humanas sobre cotidianos, corpos e mentes, fornecendo o aval científico de que o procedimento jurídico tanto necessita para respaldar suas sentenças.

Os adolescentes considerados infratores transbordam nos excessos das ruas e casas, nas páginas de processos esquecidos em algum arquivo, nos inventários de culpas tecidos por neutralidades de toda ordem, transbordam, enfim, em uma sociabilidade autoritária reproduzida por eles e legitimada pelos defensores do combate ao malestar, que incapazes de dizer sim, insistem no não da moral do ressentimento, duplo fraterno da vingança e da educação pelo medo. 


\section{CRIANÇAS E ADOLESCENTES NA NAU DAS REFORMAS}

A Primeira República, no Brasil, inaugura o conceito de menoridade, não mais vinculado a correlações etárias, mas associado ao conceito de marginalidade em situações de abandono ou de delito. O abandono é visto como o prenúncio do risco do delito, condição tratada, na época, como caso de polícia.

A década de 20 opera a passagem da simples repressão para o afastamento das crianças dos focos de contágio, que consistia, basicamente, na idéia de que as crianças deveriam ser retiradas das ruas para se submeterem a medidas preventivas e corretivas, que estariam a cargo de instituições públicas. O Código de Menores Mello Matos, de 1927, consolida legalmente esta prática de prevenção ligada ao ideário de periculosidade.

$\mathrm{O}$ discurso que permeia todo o direito penal moderno tem como um dos principais pressupostos o conceito de periculosidade, assentado no saber do exame que comporta uma argumentação exterior ao próprio direito, mas, simultaneamente, incorporada por ele. É um ideal de higiene e saúde pública que informa o discurso jurídico desde o final do século passado, assumindo um caráter fundamental para os defensores da doutrina da periculosidade, que se encontram balizados pelas prerrogativas da Escola de Defesa Social, fundada por Fran von Liszt e Adolph Prins, dirigentes do grupo tedesco-belga no Congresso de 1910, realizado em Bruxelas pela União de Direito Penal.

O Código de Menores de 1927 sedimenta em termos legais a idéia de correção a que deveriam ser submetidos crianças e adolescentes, entendidos legalmente como menores e qualificados como abandonados e delinqüentes, respondendo, assim, a objetivos bastante específicos, o que implicava a participação multidisciplinar de saberes. Cabia ao higienista os cuidados com saúde, nutrição e higiene; ao educador, a disciplina e instrução; e ao jurista, conseguir que a lei garantisse essa proteção e assistência. Mesmo antes da Revolução de 30 e do Estado Novo, a formalização jurídica da questão do "menor" já ultrapassava o campo policial para ser equacionada como política social.

A idéia de correção já aparece acompanhada do caráter assistencial que acompanha a prática do recolhimento dos "menores", justificando a incrementação das instituições a que estes eram destinados. A criação do Serviço de Assistência a Menores (SAM), em 1941, representou a ressonância deste assistencialismo e consolidou, no campo da proteção a crianças e adolescentes, a política de bemestar social em sentido amplo, inaugurada sob o autoritarismo de Vargas.

O Código de Menores de 1979, dando continuidade à associação abandono-pobreza-marginalidade, não se limita apenas à idéia de correção, mas, respondendo a uma política de segurança, implanta uma prática institucional de reintegração coadunada com a proposta da Política Nacional do Bem-Estar do Menor (PNBM).

"Reduzir a tese de associação positiva entre criminalidade e classes sociais é próprio de uma percepção empiricista da sociedade que por meio do próprio discurso político de uma instituição passa a dar justificativa para seu próprio funcionamento. Na verdade, essa associação positiva favorece a reprodução das desigualdades na medida em que estas se erguem na sociedade por diferenciações individuais expressas nos comportamentos dos indivíduos, a partir de uma maior ou menor introjeção dos valores considerados essenciais. Considera-se desajustado ou delinqüente todo aquele que fere com sua ação à ordem, sintetizada no crime contra o patrimônio" (Passetti, 1982:79).

Segundo o autor, a criação da Política Nacional do Bem-Estar do Menor, fundamentada no pensamento da Escola Superior de Guerra (ESG), mostrou-se como uma eficaz possibilidade de equacionar um problema social, por um lado demonstrando a seleção estratégica operada pelo Estado para o problema social em si e, por outro, apontando como esta escolha vinha se ajustar aos mecanismos de controle acionados pelo próprio Estado, correspondendo a um determinado perfil de organização política. O Código de Menores de 1979, coadunado com a política social da ditadura militar e sob a rubrica de situação irregular, fundamenta-se nos mesmos preceitos que nomeiam a figura do delinqüente, o indivíduo perigoso, a associação pobreza-marginalidade e a idéia de defesa social, retraduzindo, sob a forma de segurança nacional, o subversivo por delinqüente, uma suposta minoria por outra suposta maioria.

O ano de 1979 foi declarado, conforme decisão da Assembléia das Nações Unidas, Ano Internacional da Criança. Marcou, historicamente, o momento em que a pesquisa sobre a criança no Brasil floresceu de maneira sistematizada, levando à articulação de diversos grupos voltados para a defesa dos direitos de crianças e adolescentes, que, desde esse momento, já direcionavam suas críticas ao Código de Menores promulgado no mesmo ano. Tais críticas questionavam a chamada "situação irregu- 
lar" ali preconizada, na medida em que esta reiterava um padrão de normalidade e legitimava o recolhimento de todos aqueles que fugissem do padrão de comportamento esperado. Práticas como estas, no interior de cada grupo de defesa de direitos e suas respectivas articulações, foram fundamentais para fomentar, durante uma década, o perfil social que deveria pautar uma nova legislação referente a crianças e adolescentes, consolidada com a promulgação do Estatuto da Criança e do Adolescente (ECA) em 13 de julho de 1990.

O ECA veio redimensionar a possibilidade de diferenciação do atendimento destinado a crianças e adolescentes, priorizando seu desenvolvimento no interior do convívio familiar, ressaltando um caráter educativo que deve ser privilegiado a partir da família, de forma diversa ao Código de Menores de 1979, que propugnava a positividade da instituição ressocializadora, supostamente capaz de suprir as falhas na sociabilidade primária, ocasionadas pela convivência com a chamada família desestruturada.

Outra descontinuidade do ECA em relação ao Código de Menores de 1979 é a de dirimir a suspeita sobre os empobrecidos, ao não partir do pressuposto econômico para entender a situação particular vivida por crianças e adolescentes, mas priorizar o empobrecimento como causa geral e o atendimento como particular, investindo em um tipo de sociabilidade cuja definição não seja mais calcada em reducionismos econômicos, ainda que imprima certo vínculo direto entre pobreza estrutural e medidas estatais assistencialistas.

O Código Penal, em vigor até hoje, foi promulgado em 1940, sob a égide de um governo ditatorial, o Estado Novo, e é este código que rege a aplicação que a prática judiciária atual faz do Estatuto da Criança e do Adolescente, ao correlacionar ato infracional a crime e medida socioeducativa a pena, balizando-se por uma ótica penalizadora, em detrimento do perfil pedagógico que pode ser descoberto no Estatuto.

No entanto, o que se constata na histórica política do Brasil República é que tanto em períodos ditatoriais como em períodos de distensão democrática, a intervenção em nome do bem-estar acompanhou o ideal de desenvolvimento, intimamente ligado à idéia de segurança. A conduta intervencionista do Estado brasileiro consiste, desde o princípio, em privilegiar o desenvolvimento de programas e políticas sociais que, em nome da defesa do bem-estar dos infratores, encontrou uma maneira eficaz de justificar o aumento da burocracia e dar uma satisfa- ção à opinião pública, ajustando-se, confortavelmente, com o cunho autoritário da gestão da vida.

Se o Estatuto da Criança e do Adolescente ainda apresenta lacunas em várias passagens e mantém resquícios do ranço assistencialista, preconizado pelas políticas sociais, seu advento, porém, inaugura, em termos jurídicos, uma posição nunca antes tomada em relação a crianças e adolescentes no Brasil - dentre os avanços do Estatuto deve ser ressaltado o direito à ampla defesa, instaurando a figura do advogado da criança -, concebendo-os como sujeitos de direitos no presente e priorizando a formação destes futuros cidadãos, fundamentada em uma mentalidade pedagógica e respaldada na opção preferencial pela liberdade.

Acreditou-se, por motivos óbvios, que o Código de Menores de 1979 estava de uma vez por todas sepultado e definitivamente já não era o referencial legislativo que orientaria o Estado, a Justiça e a sociedade no atendimento a ser dado a crianças e adolescentes. Contudo, a Justiça vem insistindo em ler o ECA sob a lente encarceradora do Código de Menores, que, no cotidiano da prática judiciária, sobreviveu como um cadáver insepulto. Onde o ECA prevê a excepcionalidade, promotores e juízes, pela ação, advogados pela omissão e técnicos pela reconstrução científica da figura do delinqüente apreendem a regra, transformando a internação em regularidade.

Da disciplinarização à multidisciplinaridade, o objeto de repressão, com maior ou menor dor, da mesma maneira que o objeto de consentimento, é pensado como certeza centralizadora que em nome de todos beneficia o particular e exige cada vez mais a omissão: a individualidade perdida como meta de controle.

\section{O TRIBUNAL}

A defesa dos direitos de crianças e adolescentes calcada na aplicação regular que a Justiça faz do ECA reserva aos adolescentes, chamados infratores, a parcela de sociabilidade que lhes cabe, sob a forma de restauração da personalidade "quase perdida", baseada no saber científico acoplado à sentença jurídica, aquela que diz ser capaz de instruir para suprir as deficiências na sociabilidade.

Quando o adolescente, considerado infrator, adentra no espaço do tribunal, a vestimenta austera é um dos elementos de visibilidade que demarca algumas extensões dessa instituição com a qual ele se depara como território da autoridade por excelência. A disposição espacial dos objetos e das pessoas transcreve a racionalização utilitá- 
ria do minúsculo ao operacionalizar taticamente o "cálculo da anatomia política do detalhe" (Foucault, 1987) do direito penal moderno.

Este cálculo baliza a penalização para além do ato cometido. Na verdade, estes adolescentes não são punidos pelo que fizeram, mas pelo que podem vir a fazer. A inquisição a que são submetidos não percorre apenas atos, pessoas e objetos, mas vasculha almas, tratadas pela mentalidade punitiva como formas desabitadas que devem estar a serviço do procedimento legal.

Estes adolescentes experimentaram situações que os colocaram diante de circunstâncias de convívio autoritário e, por conseguinte, foram também se sociabilizando autoritariamente, submetidos a uma educação na qual preponderou o "sim" ou o "não", e que se mostrou para eles, na maioria das vezes, como única possibilidade de lidar com o outro, seja no âmbito público ou privado. Diante de uma justiça penalizadora, seus atos não deixarão de ser compreendidos como práticas criminosas.

Não se trata mais da pessoa do infrator ou da noção da infração, como prevê o ECA, mas do investimento de um saber técnico-científico sobre a edificação da personalidade delinqüencial desses adolescentes, que se caracteriza como pressuposto para sua própria existência. O saber do exame (Foucault, 1973), incorporado pelo direito penal moderno, não opera, tal qual o modelo do saber do inquérito, sobre a pesquisa da verdade, mas trabalha todo o tempo na construção de uma verdade acerca desse sujeito transgressor caracterizado pela figura do delinqüente ou criminoso.

O tribunal, tomado como foco de discussão do sistema penalizador, estabelece um deslocamento na discussão acerca do encarceramento de crianças e adolescentes. A reflexão não se centra mais no cárcere em si, mas privilegia o "campo" anterior deste mesmo sistema, ao explorar o espaço do tribunal no seu sentido restrito (o entre paredes) e como um dos elementos da tecnologia carcerária. Sua eficácia reside na capacidade de estabelecimento de um "território" mais amplo. ${ }^{2}$

O tempo de julgamento é incorporado como campo contínuo ao do cárcere, na medida em que o processo penal, lançando mão de mecanismos de mortificação, ou, mais especificamente, de normalização do indivíduo, não apenas antecede, como antecipa o tempo do encarceramento.

A forma que circunda o tempo e o espaço do julgamento faz emergir sua arquitetura discursiva, não em seu sentido técnico, mas contemplando diversas comunicações de saber e poder que constroem e edificam discursos regulares, articulados a uma arquitetura espacial e temporal que se mostra e se esconde nas falas dos processos. Os espaços discursivos formalizados se intercambiam durante o desenvolvimento do processo jurídico (sindicância) referente à apuração de ato infracional atribuído a adolescentes.

O não dito e o não lugar deste discurso transitam no espaço da palavra proferida e ao se referirem à coisa que nomeia, estabelece e organiza silêncios constitutivos da própria escuta técnico-jurídica sobre seu objeto de saber. Este silêncio não se refere apenas à composição de cada processo em particular, nos quais de alguma forma se reconta a história de cada um a partir de um episódio vivido, mas denota também a utilidade do silêncio na história no que tange à infância e adolescência no Brasil.

A eficácia do procedimento legal a serviço da mentalidade punitiva explicita-se quando se percebe que existem padrões de justificativa para a internação dos adolescentes considerados infratores, independentemente do tipo de infração atribuída. O primeiro padrão se refere à justificativa regular para a internação provisória, que se assenta na tríade ordem pública, personalidade violenta e integridade pessoal. O segundo padrão é constituído de forma contínua ao primeiro, já que se refere à internação propriamente dita, acrescido de um novo elemento: a dissolução da autoridade paterna. Trata-se não mais de uma tríade, mas de um quarteto: ordem pública, personalidade violenta, integridade pessoal e dissolução da autoridade paterna.

É possível perceber uma diferença óbvia em termos da duração temporal máxima prevista pelo ECA em relação à internação provisória (45 dias) e à internação máxima (três anos). Uma outra diferença é demarcada espacialmente pela circunstância de que o adolescente, mesmo tendo sido internado provisoriamente e permanecendo internado por 45 dias, ainda tem chance de ser absolvido ou receber, no final do procedimento de apuração do ato infracional a ele atribuído, outra medida que não a internação.

Entretanto, ao se conjugar a circunstância temporal com a espacial, percebe-se que no interior da diferença aparece a continuidade entre internação provisória e internação, como medida final do procedimento em que uma e outra se equivalem. A equivalência, porém, não repousa em torno da discussão do tempo mínimo de uma e do tempo máximo da outra. 
Ela é percebida quando se interroga qual o significado desta interceptação do indivíduo para ele próprio e para a sociedade, sinalizando a maneira como no interior da prática judiciária penalizadora se formaliza uma forma de gestão de vida cujo cálculo de tempo que deve ser extraído da vida dos indivíduos deve estar coadunado com espaços de eficácia adequados, onde o tempo de confinamento representa não uma garantia de integridade pessoal - para quem está fora ou dentro do cárcere -, mas responde de maneira estratégica a uma prática política de controle. Por meio de um discurso de verdade, instaura na vida da sociedade a parcela de cada indivíduo que deve ser confinada, confinando também, assim, uma parte de cada um de nós.

O promotor corporifica a fala da sociedade instituída que imprime à comunidade voz comum, interpelando o espaço circunstancial privado em nome da mensagem padronizada do público. Configura-se em agente da fala coletiva, transformando o enunciado que preserva em palavra de exclusão. O promotor (Ministério Público) simboliza a figura do vigilante na medida em que personifica o guardião do Bem-Comum. Contudo, o dito bem-comum passa a ser um conceito questionável, já que a maioria das infrações registradas é contra o patrimônio.

Sua figura do guardião do Bem-Comum associa-se à integridade física e moral do indivíduo, sendo este último a base para a materialização dos bens que ele mesmo possa usufruir, em nome da preservação do corpo do indivíduo em geral garantem-se os bens dos indivíduos particulares. Desta forma, o bem-comum é uma abstração necessária para a garantia dos bens em particular. O indivíduo passa a ser o particular e os bens o geral a ser assegurado pela impessoalidade da lei através do procedimento sob o regime da soberania.

O promotor, portanto, aquém do guardião do Bem-Comum, constitui-se no guardião de bens e, no limite, um dos interceptadores de indivíduos que ousam investir contra a propriedade.

O Direito contemporâneo, característico do Welfare State, propaga a afirmação de que a racionalidade jurídica do direito está norteada por um novo paradigma preconizado pelo direito social, que não está mais subjugado às noções universais e transcedentais da justiça, mas balanceado por interesses sociais irredutíveis.

É necessário salientar que, por um lado, o conceito de justiça social é uma falácia, pois ele não passa de um pretexto a mais para legitimar a intervenção e, por outro, é oportuno interrogar a afirmação de que o direito social tenha proporcionado uma mudança de paradigma na racionalidade jurídica, na medida em que a mesma racionalidade que privilegia a intervenção perpetua a transgressão de direitos individuais e coletivos.

O padrão das falas do promotor reproduz a rotina da internação balizada pelo princípio de negativização do indivíduo. Em nenhum momento se busca algo de positivo nesses adolescentes. Jacques Donzelot (1986) salienta que a reconstrução do indivíduo a ser encarcerado e sua vida na prisão estão fundamentadas na classificação de atributos negativos, e a perpetuação desta negatividade é que dá sentido à continuidade destas instituições.

Caso elas fossem capazes de descobrir, pedagogicamente, novos sentidos latentes nos prisioneiros, correriam o risco de autodestruição. A fala do promotor submete-se às demais quando lhe convém e referenda a dos técnicos quando a legitima, fazendo aparecer uma regularidade fundada na fala técnica dando-lhe respaldo "testemunhal" para justificar o pedido de internação ao juiz. O padrão do testemunho preferencial é explicitado não só como base de instrumentalização dos argumentos da promotoria, como sua incorporação é ressaltada sob a forma de elogio ao laudo técnico, quando este recomenda a internação. Todas as vezes que convém ao promotor, a fala externa não é incorporada, o fato de os adolescentes negarem o ato infracional é desconsiderado, adotando-se como regra geral a desqualificação da fala do adolescente e sobrepondo à sua voz a justificativa padrão legitimadora de sua internação.

A aceitação da medida de internação pedida pelo promotor e a negação das alegações do advogado são uma regularidade no procedimento do juiz, demonstrando como se estabelece uma cumplicidade constante entre a atuação do Ministério Público e a sentença do juiz, na qual um e outro existem como seu próprio duplo.

O juiz aparece no espectro da defesa da ordem pública como a incorporação da lei ou, mais precisamente, como símbolo da inscrição da lei. Contudo, esta lei não é apenas uma via de mão única objetiva e positiva, como entende a leitura meramente técnico-jurídica, mas compreende meandros mais sutis, proporcionados por sua própria premissa que reside, prioritariamente, na interpretação. Uma vez que a lei seja compreendida enquanto representação e sua aplicação como uma conseqüente interpretação de uma primeira representação, abre-se a possibilidade de se ler o cotidiano da prática judiciária como um campo de representações produtoras de realidade e práticas sociais. 
A fala do juiz, tida como a fala da imparcialidade, inscreve-se na figura do sujeito que, por si só, configura-se em representação enquanto personalização da fala da lei e agente aplicador da "justiça". Sua fala, de forma regular, revela-se pela prática em transformar a prescrição legal que preserva em palavra de inversão da realidade, valorizando o cárcere em nome do bem-comum, optando, regularmente, pela internação, formalizando, assim, a via oposta do que propugna o Estatuto da Criança e do Adolescente.

Uma primeira regularidade encontrada no padrão de internação mostra-se sob a forma de valorização do estudo biopsicosocial, que constrói a figura do delinqüente, ratificando o desempenho deste como o testemunho preferencial balizador da sentença. Outra regularidade complementar valoriza o tratamento institucional, ressaltando o fracasso contínuo do adolescente. Justifica a interceptação fundamentando-a moralmente pela influência de más companhias e pelo consumo de drogas como elementos geradores do ato infracional.

O padrão das falas do juiz ainda aglutina a associação do laudo técnico com o fracasso da família e a "afeição do adolescente ao ilícito", resultando na institucionalização, na qual a solução, supostamente, repousa no Estado.

A fala do advogado apresenta-se, regularmente, como fala da realidade dissociada; a expressão global do agente é substituída pelo indivíduo representado, portador da fala circunstancial que suprime a mensagem global do agente. Produz um enunciado formal, mesmo pleiteando a absolvição do adolescente como padrão geral; baseiase de forma recorrente nos mesmos argumentos que servem como subsídios de legitimidade para a internação. Ao se respaldar em conceitos coadunados com o Código de Menores de 1979, desqualifica seu próprio discurso e se apresenta descomprometida com seu papel de defesa, edificando uma fala de consentimento da sentença.

A figura do advogado apresenta-se sob a forma ausente da palavra não proferida, inversamente do que se espera, que a ordem pública no estado de direito pressuponha a real defesa de qualquer cidadão, e que isto inclua também o transgressor.

No entanto, se, por um lado, a prática penalizadora trabalha com o ato, como um instante suspenso no tempo, por outro, resgata condutas anteriores e paralelas, inventariando desvios e sobrepondo culpas em um somatório que acarreta a construção da "personalidade criminosa" coadunada com os parâmetros do saber do exame.

Se a figura do testemunho surge na modalidade do inquérito, sendo capaz de responder à reatualização da rea- lidade passada, e é incorporada pelo saber do exame sendo que o surgimento deste é acoplado a uma série de saberes especializados, que fazem parte da gestão de controle da regularidade dos fluxos de "vida" e de "morte" -, deve-se ressaltar que, na modalidade do exame, o testemunho comum assume apenas uma faceta formal no procedimento jurídico para a apuração do ato infracional atribuído a adolescentes, pois o testemunho legitimador da sentença não é o do homem comum, mas do homem que detém o saber sobre os caminhos e descaminhos do excesso: o saber técnico-científico. O parecer técnico é o testemunho preferencial.

O padrão dos pareceres técnicos, por meio de estudo biopsicosocial, mostra-se, regularmente, favorável à restrição da liberdade. Portador de respaldo científico, transforma a "intenção que reintegra" em palavra que personaliza o delinqüente, utilizando-se de argumentos falaciosos tais como "família desestruturada", e fazendo a perigosa associação de marginalidade e pobreza, explicita o olhar e a palavra que incrimina.

A desqualificação da família, nos pareceres técnicos, quando não é obtida pelos elementos regularmente perseguidos em seus membros - escola, trabalho, religião, renda -, é buscado no próprio adolescente, qualificado como em descompasso ao perfil familiar. Tal lógica opera pela oposição regular-irregular, desnudando uma mentalidade que pauta as regras de convivência restrita à introjeção de um único padrão de valores, aquele que responde à conduta regular.

O saber científico, subsidiando as vertentes criminológicas, vê nesses adolescentes "indivíduos marcados" e os apresenta para a "sociedade fechada" que se acredita capaz de cumprir seu papel ressocializador. No entanto, os próprios técnicos admitem que a Febem não passa de um depósito de expurgados, e mesmo assim recomendam a internação como saída cabível. Desse modo, desqualifica-se a liberdade enquanto tempo inoportuno e perpetua-se o cárcere enquanto espaço adequado.

Se o homem é e foi livre para criar tribunais sustentado por termos como culpa, inocência, perdão entre outros, de acordo com o exercício de jogos de palavras característicos de cada sociedade, como afirmam os defensores da dissuasão penal, isto não implica que o tribunal seja tomado como produto de uma liberdade positiva, em que a liberdade do outro amplia a minha, mas cabe interrogar como acontecimentos de liberdade e coação amplificaram mecanismos de mortificação da própria liberdade, quando se artificializa a convivência em nome da retórica restauradora ou reformista. 
É provável que o limite democrático repouse em seu limiar com a mentalidade punitiva, quando defende o bem para todos, o bem comum para a maioria e a ordem pública como melhor tradução da benevolência para as minorias de toda sorte, diversificando cotas de bem-estar nos estilhaços de diversidade que é capaz de suportar enquanto espelhos de si mesma.

O bem como valor maior e absoluto não produz outra coisa senão prisões, sejam elas rudimentares ou assépticas, disciplinares ou de controle, e, muito mais do que equivaler a uma pena racional econômica e politicamente quantificável, representa a explicitação dos limites da mentalidade punitiva, em qualquer tempo e lugar, edificando, reformando e consolidando o cárcere do pensamento sobre o próprio pensamento.

\section{NOTAS}

Este artigo é produto do desenvolvimento de algumas idéias presentes em minha dissertação de Mestrado: Inventários de desvios: os direitos dos adolescentes entre a penalização e a liberdade. São Paulo, PUC/SP, 1996, que diz respeito à análise de 473 processos de adolescentes oriundos de comarcas do interior do Estado de São Paulo, internados na Febem-SP, relativos aos anos de 1991 e 1992, sendo que o total de processos considerados completos foi de 299.

1. Conforme definição do Dicionário Aurélio Básico da Língua Portuguesa (Rio de Janeiro, Editora Nova Fronteira, 1988), bem-estar corresponde a estado de perfeita satisfação física ou moral; conforto. (Antônimo. mal-estar: indisposição ou perturbação orgânica, doença de pouca gravidade; incômodo. Ansiedade mal definida, inquietação. Situação incômoda, constrangimento, embaraço. (Antônimo: bemestar).

2. Os termos campo e território são utilizados aqui a partir da analítica foucaultiana, designando, respectivamente, noção econômico-jurídica e jurídico-política.

\section{REFERÊNCIAS BIBLIOGRÁFICAS}

DONZELOT, J. A polícia das famílias. Rio de Janeiro, Graal, 1986.

FOUCAULT, M. A verdade e as formas jurídicas. Rio de Janeiro, PUC/RJ, 1973. . Vigiar e punir. Petrópolis, Vozes, 1987.

PASSETTI, E. Política nacional do menor. Dissertação de Mestrado. São Paulo, Pontifícia Universidade Católica de São Paulo, 1982

OLIVEIRA, S.M. de. Inventário de desvios: os direitos dos adolescentes entre a penalização e a liberdade. Dissertação de Mestrado. São Paulo, Pontifícia Universidade Católica de São Paulo, 1996. 